\title{
Optimization of development mode of asphalt profile control based on numerical simulation and study of its mechanism
}

\author{
Fulin Wang ${ }^{1}$, Tao Yang ${ }^{1}$, Yunfei Zhao ${ }^{1}$, Yanjun Fang ${ }^{1}$, Fuli Wang $^{2,},{ }^{*}$, Gaojun Shan ${ }^{1}$, and Guangsheng Cao ${ }^{3}$ \\ ${ }^{1}$ E\&D Research Institute of Oilfield Company Ltd., 163712 Daqing, PR China \\ ${ }^{2}$ School of Electrical and Information Technology, Heilongjiang Bayi Agricultural University, 163319 Daqing, PR China \\ ${ }^{3}$ NorthEast Petroleum University, 163318 Daqing, PR China
}

Received: 17 January 2020 / Accepted: 25 March 2020

\begin{abstract}
Asphalt profile control is an effective method, which can further improve oil recovery of reservoir polymer flooded, it has a lot of advantages including high strength profile control, seal strata formation efficiency, low cost and no pollution, but there has not a perfect evaluation system for its development mode. The effect of different concentration, injection rate, radius of profile control, the timing of profile and segment combination way on the oil displacement effect of the asphalt profile control were researched using numerical simulation method on actual typical well area in Daqing oilfield, and the mechanism of asphalt profile control was studied in detail. According to the results of laboratory test, the largest Enhanced Oil Recovery (EOR) of asphalt was obtained at injection concentration $4000 \mathrm{mg} / \mathrm{L}$, and the best combination was "high-low-high" concentration slug mode. According to the results of numerical simulation, the best concentration, injection rate, radius of profile control and injection timing were $4000 \mathrm{mg} / \mathrm{L}, 0.15 \mathrm{PV} / \mathrm{a}$ (Pore Volume [PV], $\mathrm{m}^{3}$ ), $1 / 2$ of well spacing and $96 \%$ water cut in single slug of asphalt injection system, when the injection condition was multiple slug, the "high-low-high" slug combination mode was the best injection mode. These results could provide effective development basis for asphalt profile control after polymer flooding in thick oil layers.
\end{abstract}

\section{Introduction}

As the oilfield enters the extra-high water cut stage, both water flooding and polymer flooding oilfields are facing the problem of vertical or planar injection fluid inrush caused by heterogeneity (Ma et al., 2019). Profile control, as an effective method of plugging high-permeability layers, could expand sweep volume of the medium and low permeability layers, and improving the development effect, has been used as an indispensable method for oilfield development. The refinement development of oilfield requires increasingly strengthen profile control, the conventional chemical profile control agents such as gel (Hoefner et al., 1992; Pinho de Aguiar et al., 2020; You et al., 2011), volume expansion grain (Salomao and Grell, 2001), polymeric microsphere (Lakshmi et al., 2013; Lin et al., 2015), and composite ion (Liu et al., 2005) have been proposed by oil field workers to adapt to different reservoirs or development conditions, but have not been able to meet the development needs.

Asphalt profile control method began to be found gradually (Fu and Sheng, 1999; Ribeiro et al., 2009; Xiao et al., 2014), it refers that the asphalt particle (non-bulk

\footnotetext{
* Corresponding author: 57026413@qq.com
}

granular type) carried by liquid is injected into the formation, during the migration process, the mechanical filling ability of the asphalt particles and its bonding characteristics under the formation conditions lead to the blocking of the high-permeability parts in the layer, which expands the sweep volume and EOR. Asphalt particle profile control has many advantages: the asphalt particle is synthesized on the ground, which avoids the uncertainty of cross-linking reactions of conventional gel underground; the asphalt particles have injection selectivity better, a certain size asphalt particle can enter the high-permeability water flow channel in reservoir selectively, and no or a little amount of it enters the medium and low permeable layer (Ren, 2014). In addition, the water content of the oil field still rises back to ultra-high value after polymer flooding (AlSofi and Blunt, 2014), indicating that the role of polymer in reservoir plugging adjustment is not enough, and the large pore channels for injection fluids still exist after polymer flooding, thus the deepen profile control with greater intensity is needed to block the large pore passage. Asphalt derived from the stratum has little damage to the stratum and is beneficial to the subsequent reservoir reformation. Furthermore, the effect of asphalt profile control has been proved by laboratory tests (Liu et al., 2015), and it was first applied in Daqing oilfield, has achieved a better effect, but there is 
not a perfect and systematic evaluation for its development mode. The objective of this study was to evaluate the oil displacement effect of asphalt profile control in typical well areas and optimize its development mode, and to elaborate the asphalt profile control mechanism in detail, and to provide basis for effective asphalt profile control after polymer flooding in thick oil layers.

\section{Laboratory experimental study on profile control of asphalt particles}

\subsection{Materials}

Asphalt Particle Profile Control Fluids (APPF) with different concentrations were injected into three-layer heterogeneous cuboid cores $(4.5 \mathrm{~cm} \times 4.5 \mathrm{~cm} \times 4.5 \mathrm{~cm})$ with diversion sections. The measured permeability of every layer is 500,1500 , and $3000\left(10^{-3} \mu^{2}\right)$ respectively. The asphalt particle sizes were $0.06-0.1 \mathrm{~mm}$ and $0.1-0.3 \mathrm{~mm}$ respectively, which were mixed in a ratio of 1:1 to obtain the asphalt particle profile control fluid. The reservoir temperature was $45^{\circ} \mathrm{C}$, and the experimental process was performed under the reservoir temperature condition.

\subsection{Concentration optimization of asphalt profile control}

The core geometry and dry weight were determined with Electronic Scale. The Pore Volume (PV) of the core was measured after vacuuming and saturating with water. The oil was saturated into the core and the oil saturation of the core was measured. The water was injected until to $98 \%$ of water content, and then a $0.85 \mathrm{PV}$ polymer solution was injected, and the water was flooded until to $98 \%$ of water content. Afterwards, APPF with different concentrations (1000-5000 mg/L) were injected at the rate of $3 \mathrm{~mL} / \mathrm{min}$, and then water was flooded until to $98 \%$ of water content. The pressure values of each stage under stable condition were recorded, and the permeability before and after plugging, water-flood oil recovery efficiency and polymer drive oil recovery efficiency were measured respectively.

The oil recovery efficiency and permeability under different conditions are shown in Table 1 . The water-flood oil recovery efficiency increased first and then decreased with increasing concentration of injected asphalt profile control fluid. On the other hand, the Enhanced Oil Recovery (EOR) obtained by subtracting oil recovery of polymer flooded from the oil recovery of asphalt profile also increased slowly first and then decreased with increasing concentration of injected asphalt profile control fluid. The largest EOR was obtained at the concentration of $4000 \mathrm{mg} / \mathrm{L}$ injected asphalt profile control fluid. Therefore, $4000 \mathrm{mg} / \mathrm{L}$ could be used as the optimum injection concentration of profile control fluid.

\subsection{Optimization of asphalt slug concentration combination}

Three concentrations of asphalt profile control fluids (high, $5000 \mathrm{mg} / \mathrm{L}$; medium, $3500 \mathrm{mg} / \mathrm{L}$; and low, $1500 \mathrm{mg} / \mathrm{L}$ ) were combined into different slug methods for experiments. The three-layer heterogeneous saturated oil core with diversion section was flooded with water to $98 \%$ water content, and was injected with $0.85 \mathrm{PV}$ polymer, and then flooded with water to $98 \%$ water content again. Afterwards, APPF were injected into oil core according to different slug combination modes (high-low-high, low-high-low, low-medium-high, high-medium-low, and medium-low-high), and then waterflooding was performed until to $98 \%$ of water content. The oil recovery efficiency at different stages was compared, and the best slug combination mode for APPF with different concentrations was determined according to the EOR value.

The different slug combination modes substantially affected the oil displacement effect of APPF (Tab. 2). Among them, the "high-low-high" was the best concentration slug combination due to that the EOR was increased by $6.68 \%$. And "medium-low-high" had the lowest effect on oil displacement because the EOR was only increased by $4.79 \%$. These results might be due to the fact that high-low-high concentration slug combination guaranteed the transport capacity of asphalt particles, and its posthigh-concentration slug effectively delayed the subsequent water injection breakthrough on the basis of sealing the high permeability layer. The low-concentration slug had a relatively poor plugging effect and a weak ability to improve the profile when "medium-low-high" of slug combination mode was used. Therefore, the use of the high-lowhigh concentration slug combination mode had the best effect on oil displacement.

\section{Numerical simulation of profile control of asphalt particles}

\subsection{Model establishment based on numerical simulation}

Wells group Z4 (actual typical well area in Daqing oilfield with 12 injection wells and 16 production wells) was used as the research object. Its parameters included an effective thickness of $14.6 \mathrm{~m}$, the average permeability of $820 \mathrm{mD}$, and it was developed by oblique line well pattern $(250 \mathrm{~m} \times 250 \mathrm{~m})$. It was polymer-injected in January 2004, and gradually transferred to the succeeding water flooding after December 2009. The water content was $94.4 \%$, and the oil recovery efficiency was $51.8 \%$, when polymer injection stopped. After water flooding, water content was $96.25 \%$ and total oil recovery efficiency reached to $53.4 \%$.

The profile control effect was predicted with numerical simulation method using Eclipse software. In order to ensure the precision of simulation and prediction accuracy, a $25 \mathrm{~m} \times 25 \mathrm{~m}$ planar mesh was established, and 40 small layers (0.5 $\mathrm{m}$ of thickness) were subdivided in the longitudinal direction. The total grid number was $62 \times 62 \times 40=153760$.

\subsection{Scheme design and development}

Asphalt injection was performed from November 2013 to June 2014, and the water content and cumulative oil production were predicted until to December 2018. The effects of APPF with different concentrations $(1000,1500,2000$, 
Table 1. Recovery efficiency and permeability before and after plugging at different asphalt concentrations.

\begin{tabular}{|c|c|c|c|c|c|c|}
\hline \multirow{2}{*}{$\begin{array}{l}\text { Asphalt } \\
\text { concentration } \\
\left(\mathrm{mg} \mathrm{L}^{-1}\right)\end{array}$} & \multirow{2}{*}{$\begin{array}{l}\text { Permeability before } \\
\text { asphalt injection } \\
\quad\left(10^{-3} \mu \mathrm{m}^{2}\right)\end{array}$} & \multirow{2}{*}{$\begin{array}{l}\text { Permeability after } \\
\text { asphalt injection } \\
\quad\left(10^{-3} \mu \mathrm{m}^{2}\right)\end{array}$} & \multicolumn{3}{|c|}{ Oil recovery efficiency $(\%)$} & \multirow[b]{2}{*}{$\begin{array}{c}\text { EOR } \\
(\%) \\
\end{array}$} \\
\hline & & & $\begin{array}{l}\text { Water flood to } \\
\text { water cut } 98 \%\end{array}$ & $\begin{array}{c}\text { Polymer } \\
\text { flood }\end{array}$ & $\begin{array}{c}\text { Asphalt } \\
\text { injection }\end{array}$ & \\
\hline 1000 & 1213 & 512 & 39.24 & 49.11 & 51.34 & 2.23 \\
\hline 1500 & 1245 & 502 & 37.21 & 49.23 & 51.73 & 2.50 \\
\hline 2000 & 1208 & 486 & 39.62 & 48.32 & 51.23 & 2.91 \\
\hline 2500 & 1195 & 475 & 40.12 & 48.54 & 52.24 & 3.70 \\
\hline 3000 & 1192 & 452 & 41.05 & 48.75 & 54.22 & 5.47 \\
\hline 3500 & 1241 & 431 & 41.26 & 49.14 & 55.64 & 6.50 \\
\hline 4000 & 1196 & 423 & 41.87 & 49.24 & 57.52 & 8.28 \\
\hline 4500 & 1206 & 415 & 39.15 & 48.75 & 55.21 & 6.46 \\
\hline 5000 & 1216 & 412 & 38.36 & 48.24 & 54.64 & 6.40 \\
\hline
\end{tabular}

EOR, Enhanced Oil Recovery.

Table 2. Oil recovery efficiency at different slug combination modes.

\begin{tabular}{lcccc}
\hline Different concentration slug combination & \multicolumn{2}{c}{ Oil recovery efficiency (\%) } & \multirow{2}{*}{ EOR (\%) } \\
\cline { 2 - 4 } & Water flood & Polymer flood & Asphalt injection & \\
\hline High-low-high & 34.23 & 49.46 & 56.14 & 6.68 \\
Low-high-low & 41.02 & 49.97 & 55.36 & 5.39 \\
Low-medium-high & 39.26 & 50.89 & 56.22 & 5.33 \\
High-medium-low & 40.30 & 52.87 & 58.24 & 5.37 \\
Medium-low-high & 40.34 & 51.56 & 56.87 & 5.31 \\
\hline
\end{tabular}

EOR, Enhanced Oil Recovery.

2500, 3000, 3500, 4000, 4500, and $5000 \mathrm{mg} / \mathrm{L})$, injection speed $(0.10,0.12,0.13,0.15$, and $0.17 \mathrm{PV} / \mathrm{a})$, profile control radius $(1 / 3,1 / 2$, and $2 / 3$ of well spacing), asphalt profile timing (95\%, 96\%, and $97 \%$ of water content) and slug combination mode (high-low-high, low-high-low, lowmedium-high, high-medium-low, and medium-low-high) on water content and cumulative oil production were determined by single factor numerical simulation test (Tab. 3).

\subsection{Results and discussion}

\subsubsection{Injection concentration of asphalt particle}

Based on the actual field injection rate, the injection asphalt concentration was optimized. The water content decreased and the cumulative oil production increased with increasing the injection concentration (Figs. 1a and 1b). However, the decreased amplitude of water content and the increase rate of cumulative oil production decreased gradually with the concentration increased from $1000 \mathrm{mg} / \mathrm{L}$ to $5000 \mathrm{mg} / \mathrm{L}$. The water content and cumulative oil production did not have obviously changed from the concentration of 4000$5000 \mathrm{mg} / \mathrm{L}$. Therefore, $4000 \mathrm{mg} / \mathrm{L}$ was the best injection concentration of asphalt particle.

\subsubsection{Injection speed}

The best injection speed was determined at the injection concentration of $4000 \mathrm{mg} / \mathrm{L}$ (Figs. 2a and 2b). The falling range of water cut decreased and cumulative oil production increased with the increasing injection rate. However, water cut and cumulative oil production at injection speed $0.15 \mathrm{PV} / \mathrm{a}$ were similar to that at $0.17 \mathrm{PV} / \mathrm{a}$ injection speed, indicating that the best injection speed was $0.15 \mathrm{PV} / \mathrm{a}$.

\subsubsection{Profile radius}

When the injection concentration and speed were $4000 \mathrm{mg} / \mathrm{L}$ and $0.15 \mathrm{PV} / \mathrm{a}$ (asphalt medium distribution diagram of $1 / 3$ and $1 / 2$ well spacing profile radius are shown in Figs. 3a and 3b),the effects of different profile radius on the water cut and cumulative oil production were determined (Figs. $3 \mathrm{c}$ and $3 \mathrm{~d}$ ). The profile radius of $1 / 2$ and $2 / 3$ well spacing led to the lower water content and the higher cumulative oil production than $1 / 3$ well spacing at the same period, and there were not significantly differences between $1 / 2$ and $2 / 3$ well spacing. Based on the perspective of economy, $1 / 2$ well spacing might be chosen. 
Table 3. Single factor index value of asphalt profile control.

\begin{tabular}{lcccc}
\hline $\begin{array}{l}\text { Concentration } \\
(\mathrm{mg} / \mathrm{L})\end{array}$ & $\begin{array}{c}\text { Injection } \\
\text { speed }(\mathrm{V} / \mathrm{a})\end{array}$ & $\begin{array}{c}\text { Profile radius } \\
\text { (well space) }\end{array}$ & $\begin{array}{c}\text { Profile control } \\
\text { timing (water cut) }\end{array}$ & Slug combination mode \\
\hline 1000,1500 & 0.10 & $1 / 3$ & $95 \%$ & High-low-high \\
2000,2500 & 0.12 & $1 / 2$ & $96 \%$ & Low-high-low \\
3000,3500 & 0.13 & $2 / 3$ & $97 \%$ & Low-middle-high \\
4000,4500 & 0.15 & - & - & High-middle-low \\
5000 & 0.17 & - & - & Middle-low-high \\
\hline
\end{tabular}

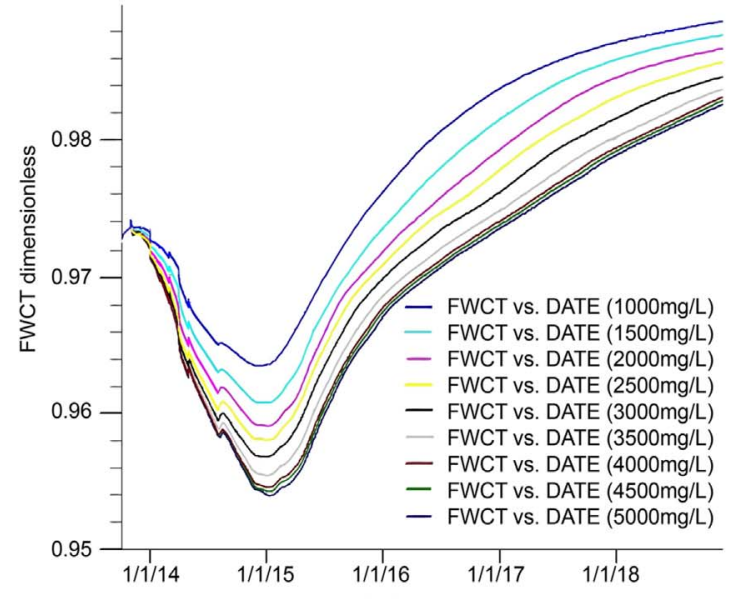

(a)

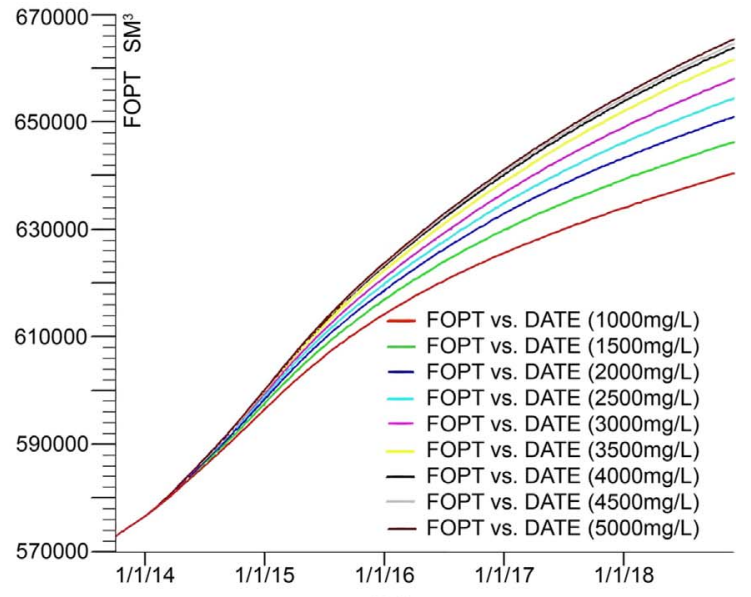

(b)

Fig. 1. (a) Water cut and (b) cumulative oil production in different periods at different asphalt concentrations.

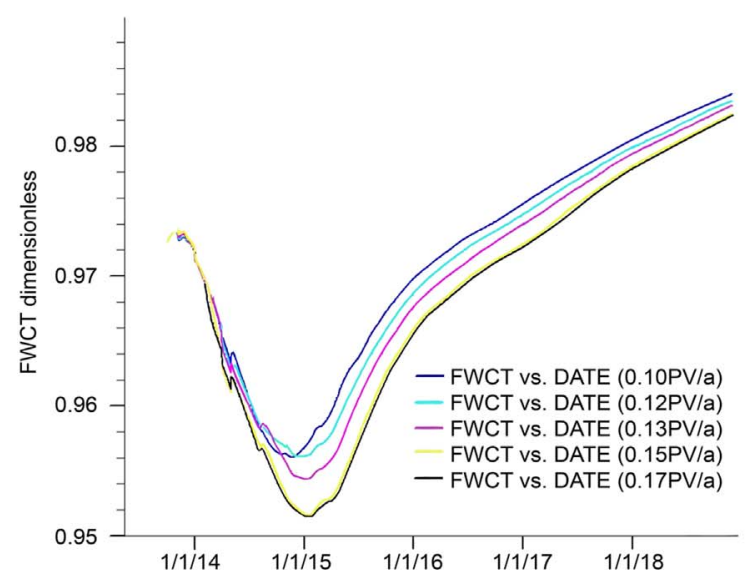

(a)

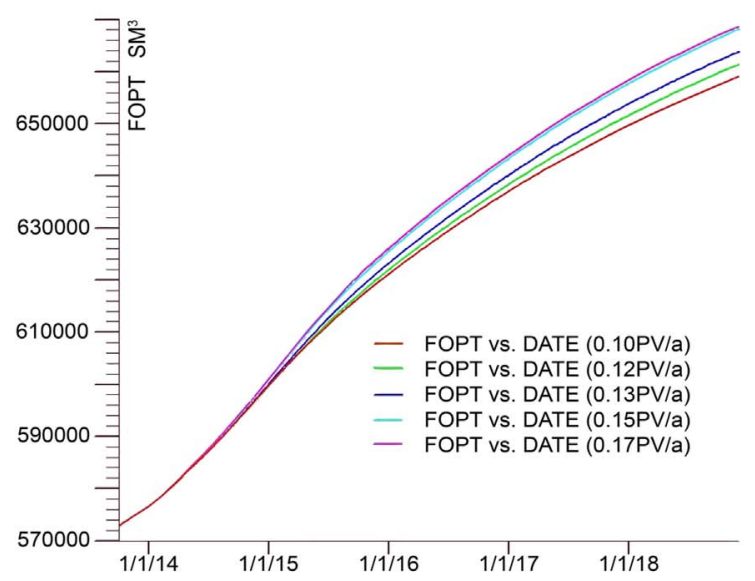

(b)

Fig. 2. (a) Water cut and (b) cumulative oil production in different periods at different asphalt injection rates.

\subsubsection{Profile control timing}

Three water cut $(95 \%, 96 \%$, and $97 \%)$ were used to determine profile control timing according to the actual water cut $(96.4 \%)$. When water cut was low, there was a better profile control effect after polymer flooding (AlSofi and
Blunt, 2014). Surprisingly, the water content of $96 \%$ was the best timing for asphalt profile (Figs. $4 \mathrm{a}$ and $4 \mathrm{~b}$ ).

The injection of APPF at a water cut of $95 \%$ resulted the lowest water cut before June 2013, and then water cut was a rapidly increase trend with time increasing, and the water cut curve caused by injection of APPF at water 


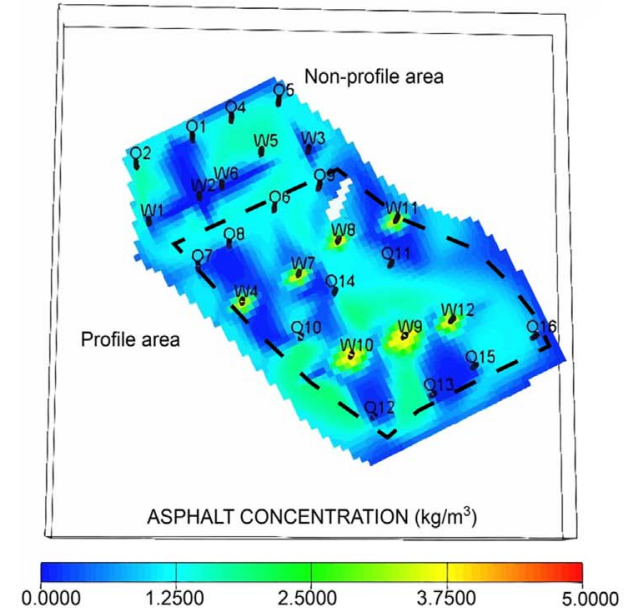

(a)

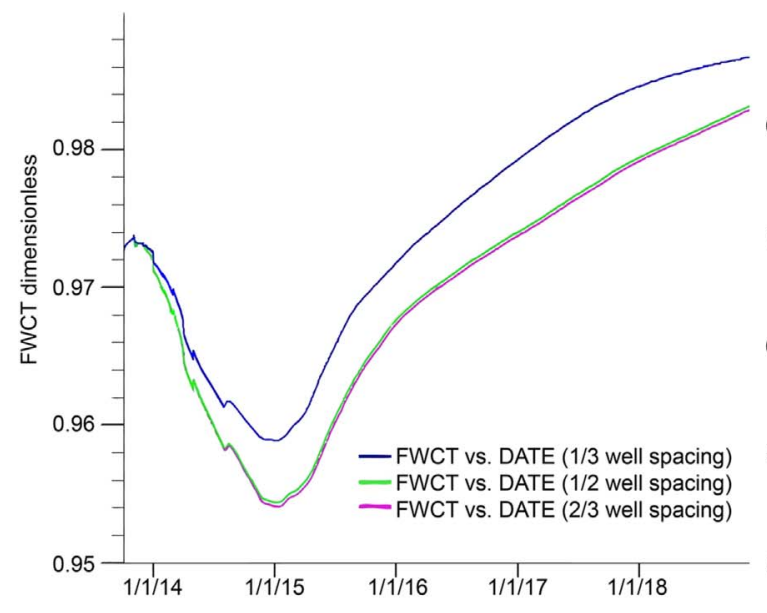

(c)

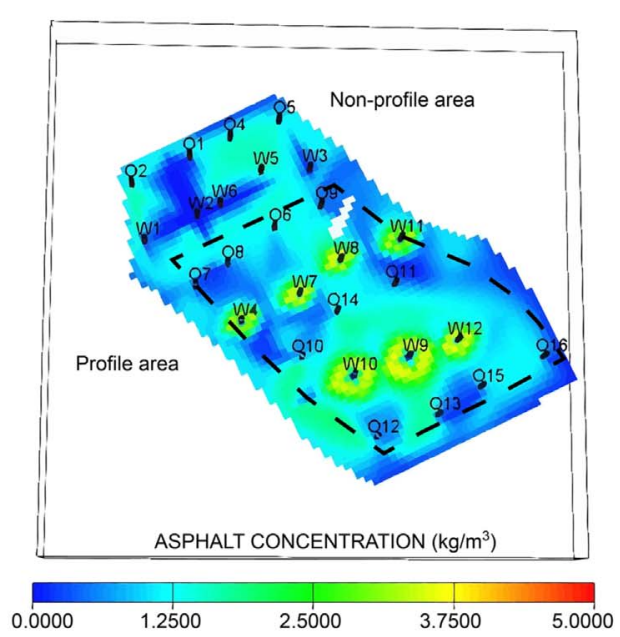

(b)

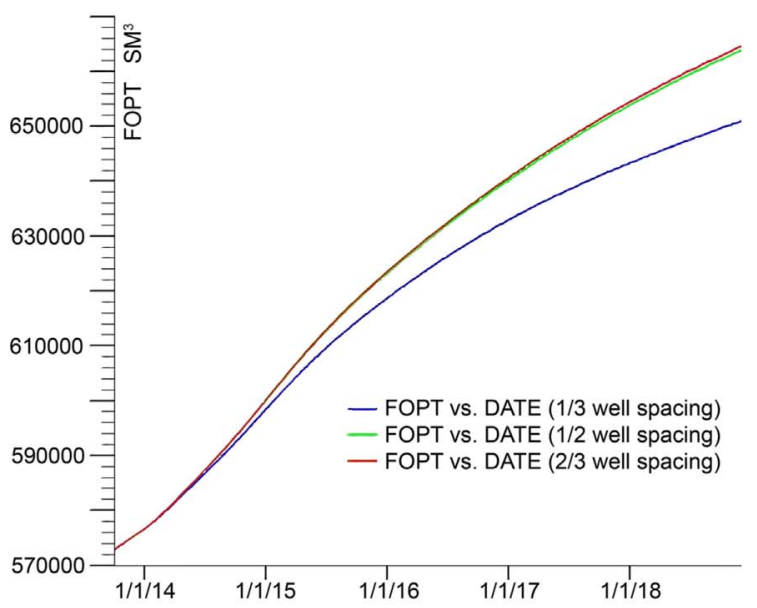

(d)

Fig. 3. Asphalt medium distribution diagram of (a) $1 / 3$ and (b) $1 / 2$ well spacing profile radius and (c) water cut of the model and (d) cumulative oil production in different periods at different asphalt profile radius.

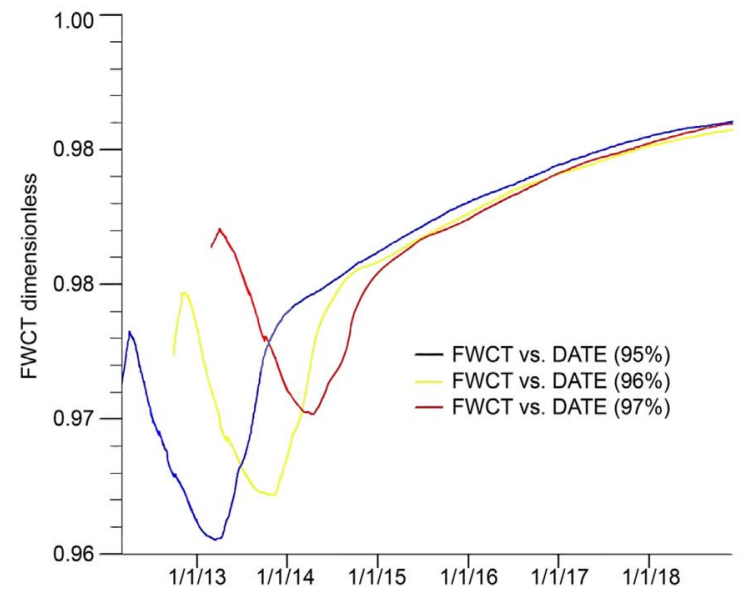

(a)

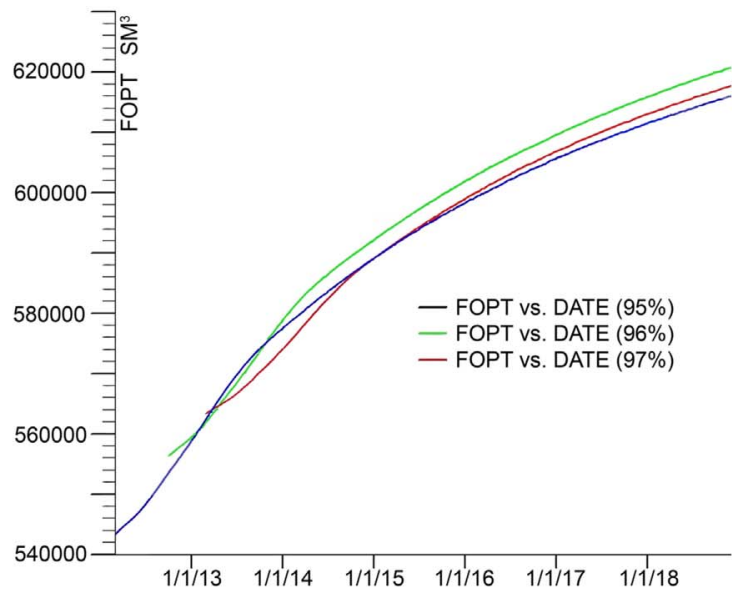

(b)

Fig. 4. (a) Water cut of the model and (b) cumulative oil production in different periods at different timings of asphalt profile control. 


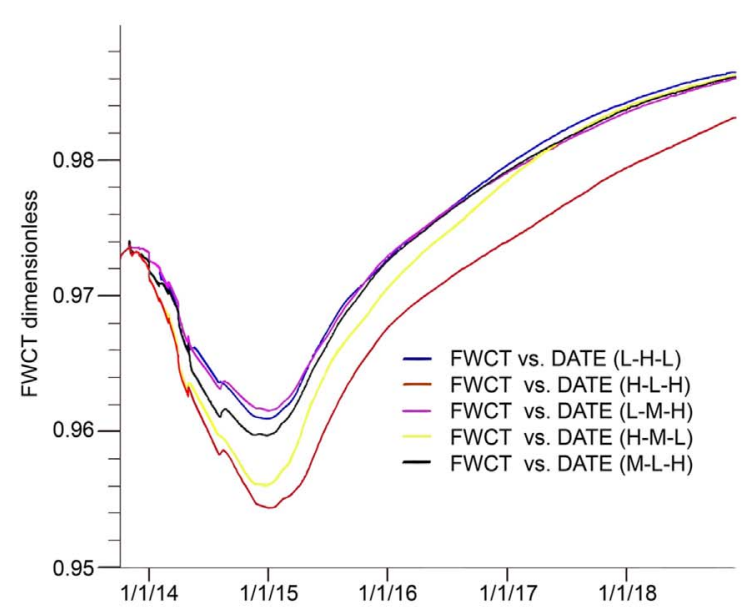

(a)

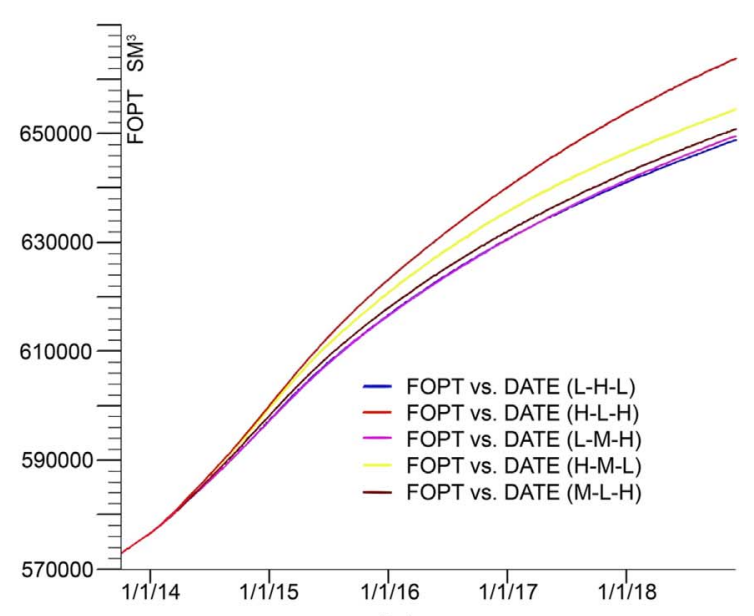

(b)

Fig. 5. (a) Water cut of model and (b) cumulative oil production for different asphalt profile control slug combination modes at different periods.

cut $95 \%$ was higher than $96 \%$ and $97 \%$ from end of 2013 to middle of 2018, and the water cut by the injection APPF at water cut $97 \%$ was slightly higher than at water content of $96 \%$. However, the cumulative oil production caused by asphalt injection at water content $96 \%$ was significantly higher than $95 \%$ and $97 \%$. Therefore, it is the best time to inject APPF when the water content is $96 \%$.

\subsubsection{Slug combination mode}

Based on the preferred optimal concentration (4000 mg/L), three concentrations (high, $4000 \mathrm{mg} / \mathrm{L} ;$ medium, $2000 \mathrm{mg} / \mathrm{L}$; and low, $1000 \mathrm{mg} / \mathrm{L}$ ) were used to set up five kinds of slug combination modes (high-low-high, lowhigh-low, low-medium-high, high-medium-low, and medium-low-high). Three injection concentrations were exchanged every three months from November 2013 to July 2014. For example, the high-medium-low means 40002000-1000 mg/L. Compared to other slug combination mode, the high-medium-high mode resulted in the lowest water cut and highest cumulative oil production at the same period, and low-high-low mode caused the lowest decrease in water content during total test period (Figs. 5a and 5b). These results were due to that high concentration slug effectively blocked the high permeability layer and improved the producing condition of middle and low permeability layers in the early, low concentration slug adjusted the middle and low permeability layers at middle period, and high concentration slug consolidated the profile control effect in the last stage, resulting in that high, middle and low permeability layers were effectively utilized and the highest cumulative oil production. But when the lowmiddle-high mode was used, low concentration slug did not closure the high permeability layer in the early, leading to the higher decline in water cut than low-high-low mode, and the increase of water cut decreased significantly due to the effect of high-concentration blocking on the hypertonic layer in the later period. The opposite result could be obtained in the high-low-high mode. Therefore, highlow-high was the best slug combination mode.

\subsection{Increasing production mechanism of asphalt profile control}

\subsubsection{Comparison of profile and non-profile development indicators}

The lowest water cut was $95.43 \%$ obtained after profile control, which was lower than $96.4 \%$ water cut before profile control. The cumulative oil predicted was $66.38 \times 10^{4} \mathrm{~m}^{3}$ until to the end of 2018 after profile control, which was higher than non-profile control.

\subsubsection{Characteristics of profile and non-profile planar seepage areas}

The profile and non-profile fluid seepage field images at the same period were compared to study increasing production mechanism of asphalt profile control. Profile control was performed in June 2014, asphalt medium was clearly discovered in profile control areas of the seepage field after eight months, but that was not found in non-profile areas (Figs. 6a and 6b).

During the process of injecting the asphalt medium in the profile control area, the asphalt medium was distributed radially around the injection well, which obviously divided the original seepage field, effectively plugged the near-well and inter-well zones, and expanded the diffusion volume of the injection agent, and had a positive effect on increasing oil production and reducing water content. However, high permeability flooded strips in non-profile areas of the seepage fields in both schemes (profile and non-profile control) did not have obvious difference and were not improved.

The seepage field images in profile and non-profile control schemes after 4 years (December 2018) was shown in Figures $6 \mathrm{c}$ and $6 \mathrm{~d}$. In non-profile scheme, the water was distributed contiguously between injection and production 


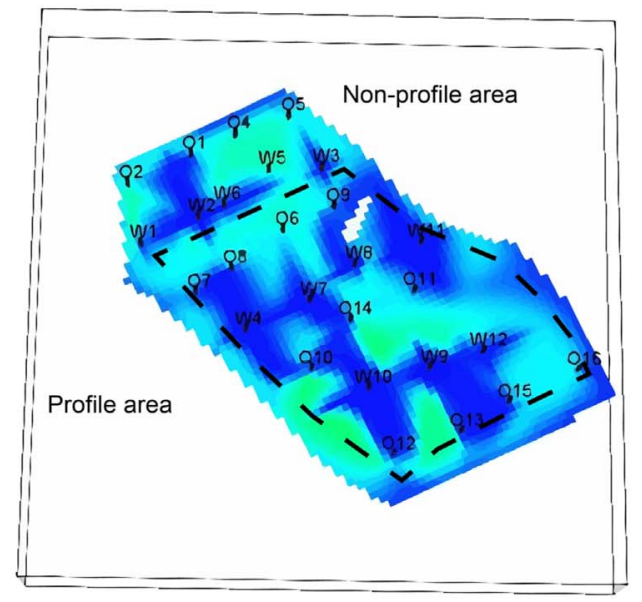

ASPHALT CONCENTRATION $\left(\mathrm{kg} / \mathrm{m}^{3}\right)$

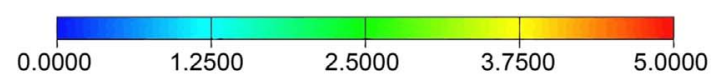

(a)

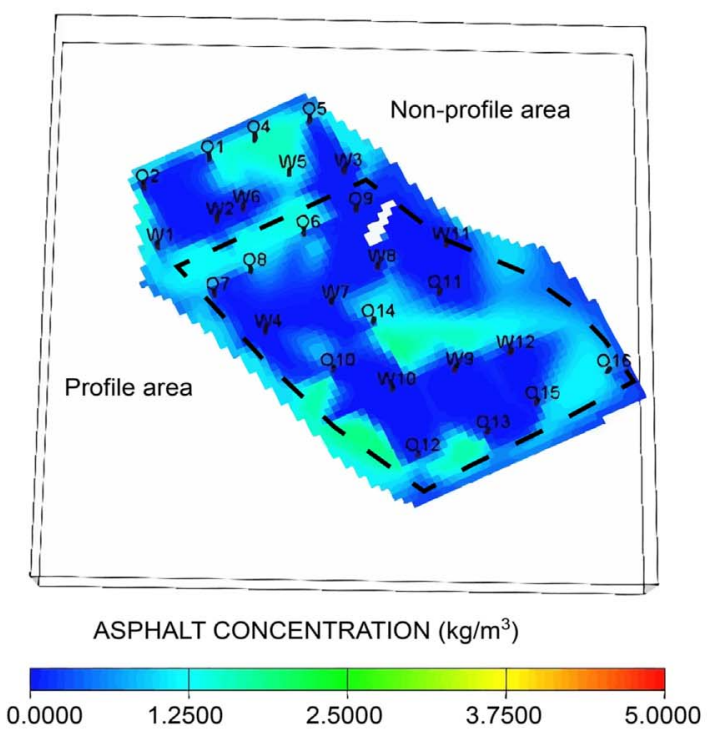

(c)
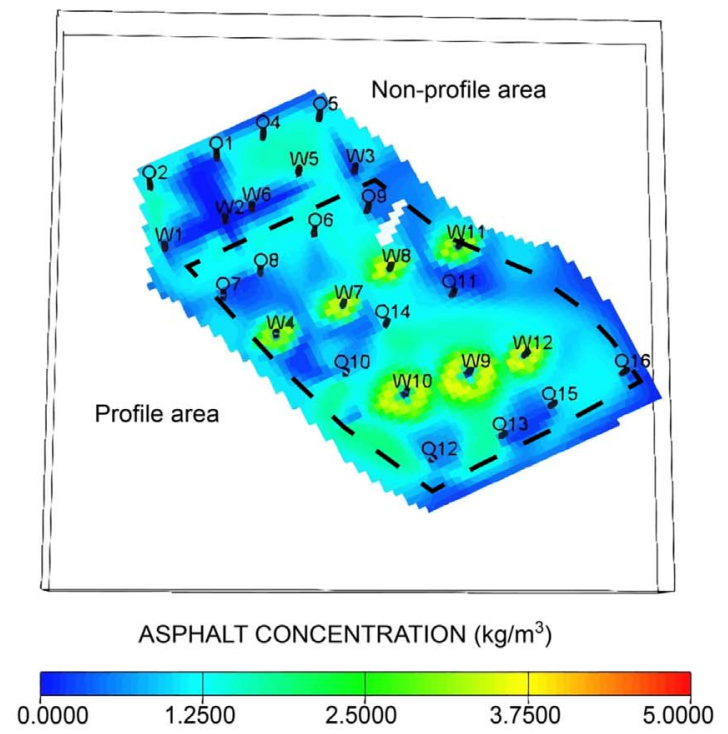

(b)
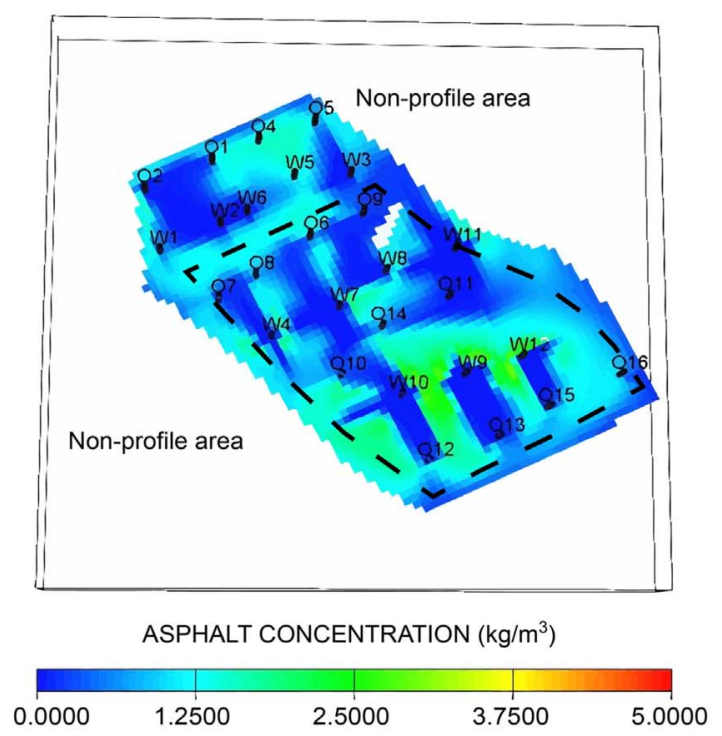

(d)

Fig. 6. Asphalt medium distribution diagram of profile and non-profile control at different period. (a) Non-profile fluid seepage field in Jun 2014; (b) profile fluid seepage field in Jun 2014; (c) non-profile fluid seepage field in Dec 2018; (d) profile fluid seepage field in Dec 2018.

well, and which between the oil wells the situation was mostly in high flooded area, which is obviously not conducive to development. However, in profile control scheme, the injection-production wells were clearly divided by the asphalt medium, which effectively prevented the formation of flooded channels between the injection-production wells and expanded the water-flood swept area.

\subsubsection{Characteristics of profile and non-profile vertical seepage areas}

In order to observe the profile and non-profile vertical seepage field characteristics, seven wells (three injection and four production) from northwest to the southeast in block floor plan were selected, including two injection wells in profile control area and one injection well in non-profile area. The joint well section was drawn (Figs. 7a and 7b). According to the profile during the profile control process in July 2014 (Figs. 7c and 7d), the reservoir using situation of the near-well zone of the two asphalt particle injection wells was very good in the profile control scheme, and producing profile in the profile control scheme was more uniform than that in the non-profile scheme, and the high and low permeability layers in the longitudinal direction were effectively produced, but the sudden phenomenon in non-profiled areas of both schemes (profile and non-profile control) was very seriously.

The profile in profile and non-profile control schemes after 4 years (December 2018) of profile control was shown in Figures $7 \mathrm{e}$ and $7 \mathrm{f}$. In the profile scheme, water onrush 


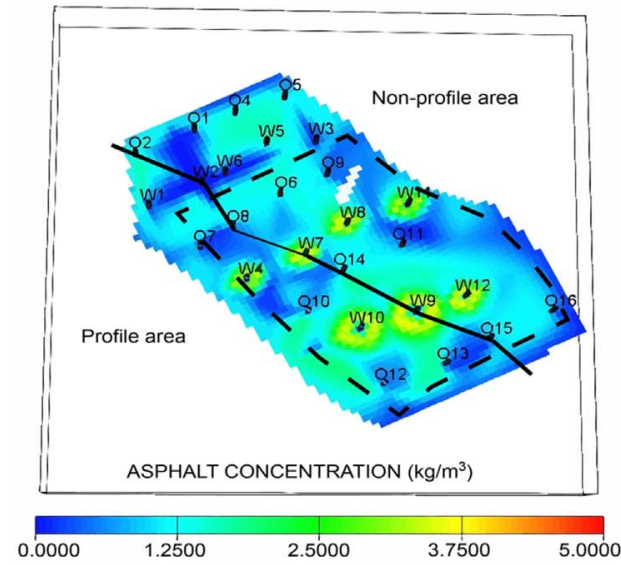

(a)

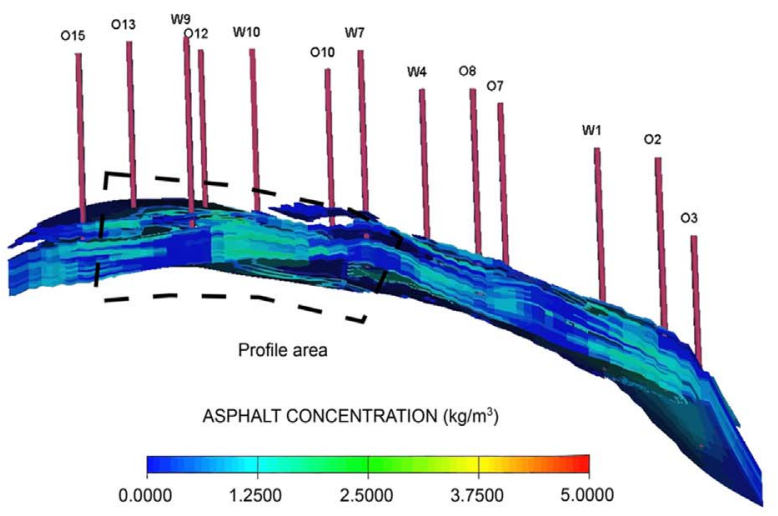

(c)

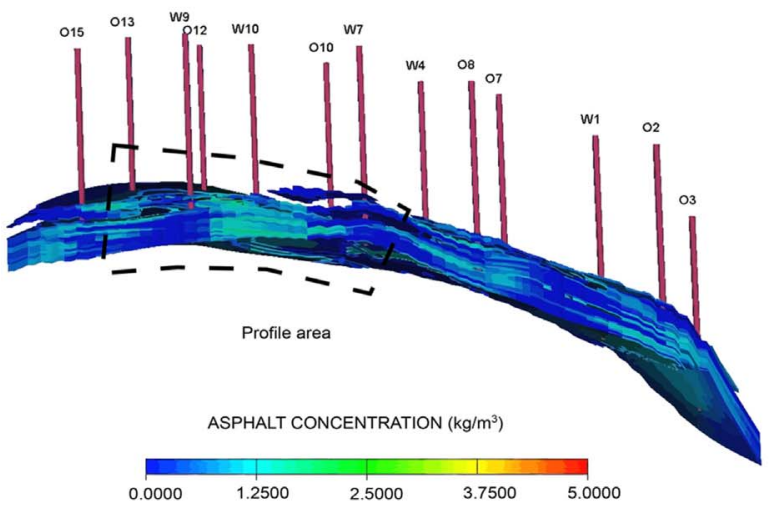

(e)

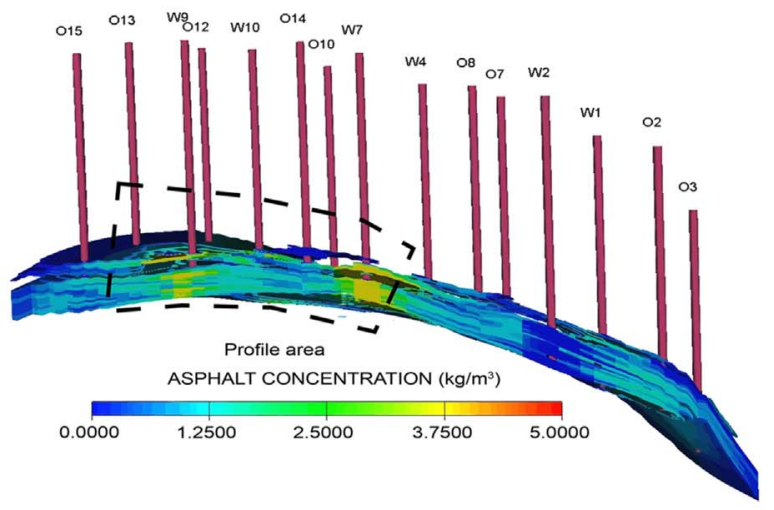

(b)

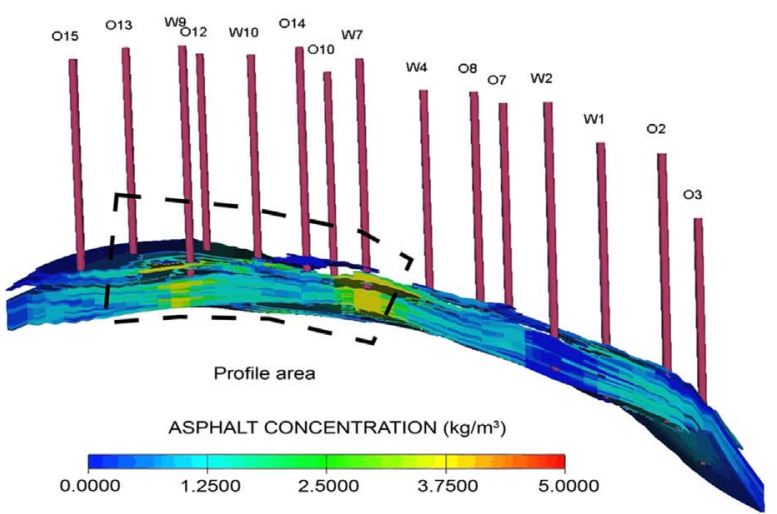

(d)

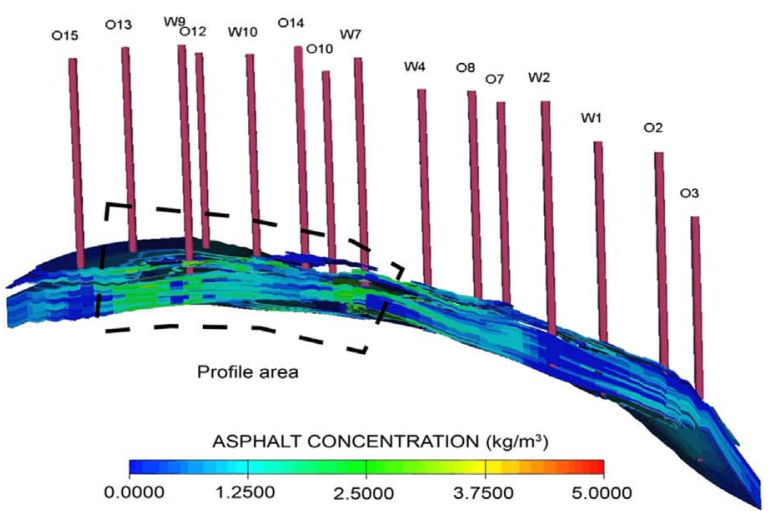

(f)

Fig. 7. Joint well profile sketch diagram, and asphalt fluid seepage diagram of profile and non-profile control schemes at different periods. (a) Joint well profile sketch diagram; (b) joint well section front view diagram; (c) non-profile fluid seepage field in Jun 2014; (d) profile fluid seepage field in Jun 2014; (e) non-profile fluid seepage field in Dec 2018; (f) profile fluid seepage field in Dec 2018.

phenomenon disappeared, and water breakthrough along in one direction and longitudinal sections of the producing status were improved, and the longitudinal swept volume was expanded, which enhanced the producing effect of oil layer.

\section{Conclusion}

According to the numerical simulation results of typical wells, the optimal profile concentration, injection speed, profile radius, and profile timing were obtained. Under 
single slug conditions, the optimal concentration, injection rate, profile control radius, and injection timing were $4000 \mathrm{mg} / \mathrm{L}, 0.15 \mathrm{PV} / \mathrm{a}, 1 / 2$ well spacing, and $96 \%$ water content, respectively. Under multi-segment conditions, the best multi-segment injection method was "high-low-high" concentration segment combination. During the injection of the asphalt medium in the profile control zone, the asphalt medium prevented the flooded channels between injection and production wells in the plane effectively, and greatly improved the unidirectional water injection breakthrough situation and the swept volume in the longitudinal direction. The asphalt profile control method could effectively block the dominant seepage channel that was not effectively blocked during the injection and polymerization process, expanded the volume of the injection agent, improved the producing degree of the medium and low permeability layers and the development effect of the block, and achieved an effective development of thick oil layers after polymer flooded.

Acknowledgments. This research is supported by National Natural Science Foundation of China (No. 51074035).

\section{References}

AlSofi A.M., Blunt M.J. (2014) Polymer flooding design and optimization under economic uncertainty, J. Pet. Sci. Eng. 124, 46-59. doi: 10.1016/j.petrol.2014.10.014.

Fu J., Sheng G. (1999) A preliminary study of asphalt from a large sulphur deposit in China by the approach of molecular organic geochemistry, J. Pet. Sci. Eng. 22, 1, 95-102. doi: 10.1016/S0920-4105(98)00059-X.

Hoefner M.L., Seetharam R.V., Shu P., Phelps C.H. (1992) Selective penetration of biopolymer profile-control gels: Experiment and model, J. Pet. Sci. Eng. 7, 1, 53-66. doi: 10.1016/0920-4105(92)90008-O.

Lakshmi D.S., Senthilmurugan B., Drioli E., Figoli A. (2013) Application of ionic liquid polymeric microsphere in oil field scale control process, J. Pet. Sci. Eng. 112, 69-77. doi: 10.1016/j.petrol.2013.09.011.
Lin M., Zhang G., Hua Z., Zhao Q., Sun F. (2015) Conformation and plugging properties of crosslinked polymer microspheres for profile control, Colloids Surf. A Physicochem. Eng. Aspects 477, 49-54. doi: 10.1016/j.colsurfa.2015.03.042.

Liu G., Jiang H., Li J., Wang M., Chen F., Ding S., Lu X. (2015) Evaluation of the performance of polymer gels mixed with asphalt particle as a novel composite profile control system, $J$. Ind. Eng. Chem. 26, 309-314. doi: 10.1016/j.jiec.2014.11.044.

Liu H., Wang J., Yang Y., Wang F. (2005) A new method for profile control with compound ion gel before polymer flooding, in: Paper presented at the SPE Middle East Oil and Gas Show and Conference, Kingdom of Bahrain. doi: 10.2118/93359-MS.

Ma K., Li A., Guo S., Pang J., Xue Y., Zhou Z. (2019) Techniques for improving the water-flooding of oil fields during the high water-cut stage, Oil Gas Sci. Technol. - Rev. IFP Energies nouvelles 74, 69. doi: 10.2516/ogst/2019042.

Pinho de Aguiar K.L.N., Frias de Oliveira P., Elias Mansur C.R. (2020) A comprehensive review of in situ polymer hydrogels for conformance control of oil reservoirs, Oil Gas Sci. Technol. Rev. IFP Energies nouvelles 75, 8. doi: 10.2516/ogst/2019067.

Ren C. (2014) Profile control technology of low-cost bitumen particles in Lamadian oilfield, J. Northeast Pet. Univ. 38, 3, 81-86. doi: 10.3969/j.issn.2095-4107.2014.03.011.

Ribeiro R.C., Correia J.C.G., Seidl P.R. (2009) The influence of different minerals on the mechanical resistance of asphalt mixtures, J. Pet. Sci. Eng. 65, 3, 171-174. doi: 10.1016/j.petrol. 2008.12.025.

Salomao M.C., Grell A.P. (2001) Uncertainty in production profiles on the basis of geostatistic characterization and flow simulation, in: Paper presented at the SPE Latin American and Caribbean Petroleum Engineering Conference, Buenos Aires, Argentina. doi: 10.2118/69477-MS.

Xiao K., Jiang H., Wang Q., Wang H., Zhao D. (2014) Adaptability study on plugging thief zones with asphalt particle in polymer flooding offshore field, in: Paper presented at the SPE Energy Resources Conference, Port of Spain, Trinidad and Tobago. doi: 10.2118/169931-MS.

You Q., Tang Y., Dai C., Shuler P., Lu Z., Zhao F. (2011) Research on a new profile control agent: Dispersed particle gel, in: Paper presented at the SPE Enhanced Oil Recovery Conference, Kuala Lumpur, Malaysia. doi: 10.2118/143514MS. 